\title{
Eye lesions in leprosy
}

\author{
G SOSHAMMA* \& N SURYAWANSHI $\dagger$ \\ * Department of Dermatology, Christian Medical College \& Hospi- \\ tal, Vellore 632 004, S. India; †Department of Ophthalmology, \\ Schieffelin Leprosy Research \& Training Centre, Karigiri, S. India
}

\section{Accepted for publication 12 October 1988}

\begin{abstract}
Summary Out of 742 out-patients screened for ocular disease, $177(24 \%)$ had eye lesions due to leprosy. These were more in the lepromatous spectrum of the disease and showed increasing trend with age of patient and duration of the disease. Madarosis was the commonest lesion (76\%). The serious and sight threatening lesions like lagophthalmos, corneal anaesthesia, corneal opacities and ulcers, iritis and complicated cataracts constituted $8 \cdot 22 \%$ of the lesions. Blindness due to corneal opacity and complicated cataract developed in 6 patients, constituting $3.4 \%$ of eye lesions with a prevalence rate of $0.8 \%$ among all the leprosy patients. Although the blinding lesions occurred in a very small percentage of patients, most of these are preventable through early recognition and institution of appropriate treatment. The simple techniques of examination to detect protentially sight threatening lesions should be taught to all leprosy workers to prevent blindness among leprosy patients.
\end{abstract}

\section{Introduction}

Estimates from India on the magnitude of ocular complications in leprosy vary from 5 to $80 \% .^{1,2}$ Such wide variations may be due to the differences in methodology of assessment, populations studied, sampling designs and definitions adopted. Without a scientifically designed study, it is difficult to establish the role of clinical or epidemiological factors in ocular lesions of leprosy.

A study was carried out on an unselected sample of patients seeking caref or leprosy and not just for eye problems. The eyes of these patients were caref ully examined using standardized techniques. This paper presents the types and extent of ocular lesions in leprosy and discusses the ocular disease from the point of view of disability and morbidity.

\section{Materials and methods}

Seven hundred and forty-two consecutive leprosy patients seen at the general out-patient clinic of the Schieffelin Leprosy Research and Training Centre, Karigiri, were included in this study.

Each patient was examined carefully and the findings on age, sex, occupation, type of leprosy, 
duration of leprosy, skin smears, details of treatment, regularity of treatment and eye findings were recorded on a modified proforma adapted from the one proposed by ffytche. ${ }^{3}$

Visual acuity was tested with Snellen's chart and only corrected visual acuity (with a pinhole or with glasses) was recorded. Patients with visual acuity not more than 3/60 in the better eye were recorded as blind. Corneal sensation was tested with a wisp of cotton. A torch and corneal loupe were used to examine all patients. All the patients in the lepromatous spectrum and any other patient with serious eye lesions were examined with a slit lamp microscope. Tension was assessed digitally. Shiotz tonometer was used to check tension if the digital tension was found to be high. Examination of the posterior segment of the eye was not attempted since it is affected very rarely. ${ }^{4}$

\section{Findings}

Out of 742 ( 537 males and 205 females) leprosy patients 177 or $23.9 \%$ had eye lesions due to leprosy. The prevalence of these lesions by age and sex are given in Table 1.

The prevalence of eye lesions increased significantly with age $(p<0 \cdot 01)$. Males are affected more than females $(p<0.01)$.

The prevalence of eye lesions by types of leprosy is given in Table 2 .

Eye lesions were significantly more in lepromatous and borderline lepromatous leprosy $(p<0.01)$. Within each type of leprosy there was no significant difference by sex.

Table 1 Prevalence of eye lesions by age and sex

\begin{tabular}{|c|c|c|c|c|c|c|}
\hline \multirow{3}{*}{$\begin{array}{l}\text { Age } \\
\text { (years) }\end{array}$} & \multicolumn{3}{|c|}{ Male } & \multicolumn{3}{|c|}{ Female } \\
\hline & \multirow{2}{*}{$\begin{array}{c}\text { No. } \\
\text { observed }\end{array}$} & \multicolumn{2}{|c|}{ Eye lesions } & \multirow{2}{*}{$\begin{array}{c}\text { No. } \\
\text { observed }\end{array}$} & \multicolumn{2}{|c|}{ Eye lesions } \\
\hline & & No. & $\%$ & & No. & $\%$ \\
\hline $0-14$ & 29 & - & $0 \cdot 0$ & 18 & 1 & $5 \cdot 5$ \\
\hline $15-34$ & 219 & 34 & $15 \cdot 5$ & 85 & 15 & $17 \cdot 6$ \\
\hline $35-64$ & 271 & 99 & $36 \cdot 5$ & 101 & 19 & 18.8 \\
\hline 65 and over & 18 & 9 & $50 \cdot 0$ & 1 & - & $0 \cdot 0$ \\
\hline Total & 537 & 142 & $26 \cdot 4$ & 205 & 35 & $17 \cdot 1$ \\
\hline
\end{tabular}

Table 2 Eye lesions by type of leprosy

\begin{tabular}{lrrr}
\hline & & \multicolumn{2}{c}{ Eye lesions } \\
\cline { 3 - 4 } Types of leprosy & No. & \\
\cline { 3 - 4 } & observed & No. & $\%$ \\
\hline Lepromatous (LL) & 163 & 92 & $56 \cdot 4$ \\
Borderline lepromatous (BL) & 155 & 48 & $31 \cdot 0$ \\
Borderline borderline (BB) & 36 & 3 & $8 \cdot 3$ \\
Borderline tuberculoid (BT) & 328 & 32 & $9 \cdot 8$ \\
Tuberculoid T) & 22 & 1 & $4 \cdot 5$ \\
Indeterminate (I) & 24 & 1 & $4 \cdot 2$ \\
Neuritic (N) & 14 & - & - \\
\hline Total & 742 & 177 & $23 \cdot 9$ \\
\hline
\end{tabular}


Table 3 Eye lesions by duration of leprosy

\begin{tabular}{lcrc}
\hline & & \multicolumn{2}{c}{ Eye lesions } \\
\cline { 3 - 4 } Duration (years) & $\begin{array}{c}\text { No. } \\
\text { observed }\end{array}$ & No. & $\%$ \\
\hline$<5$ & 392 & 64 & $16 \cdot 3$ \\
$\geq 5$ & 350 & 113 & $32 \cdot 3$ \\
\hline Total & 742 & 177 & $23 \cdot 9$ \\
\hline
\end{tabular}

Table 4 Eye lesions in relation to bacterial index (BI)

\begin{tabular}{lcrc}
\hline & & \multicolumn{2}{c}{ Eye lesions } \\
\cline { 3 - 4 } Skin smears & $\begin{array}{c}\text { No. } \\
\text { observed }\end{array}$ & No. & $\%$ \\
\hline Negative & 412 & 52 & $12 \cdot 6$ \\
BI $<2 \cdot 0$ & 118 & 26 & $22 \cdot 0$ \\
BI $\geq 2 \cdot 0$ & 185 & 94 & $50 \cdot 8$ \\
Not available & 27 & 5 & $18 \cdot 5$ \\
\hline
\end{tabular}

The prevalence of eye lesions in relation to duration of the disease is shown in Table 3.

Those having leprosy for more than 5 years had a significantly higher prevalence of eye lesions than those who had leprosy for less than 5 years $(p<0 \cdot 001)$.

The prevalence of eye lesions by skin smear results at the time of initial visit to the hospital are shown in Table 4.

Frequency of eye involvement is directly proportional to the severity of disease as judged by bacterial index $(p<0 \cdot 01)$.

The various eye lesions and their relationship to the types of leprosy are shown in Table 5.

Madarosis was the most frequent eye lesion and was seen in lepromatous and borderline leprosy. Among the lid lesions, lagophthalmos was the commonest and was seen in 30 patients. Two of these in addition had ectropion, 1 patient had entropion with trichiasis. Lagophthalmos was higher in BT cases as compared to LL or BL cases, but the difference was not statistically significant. Lagophthalmos was associated with diminished corneal sensation in 15 patients. Among the other 15 patients, 5 had a history of type I or type II reaction. Of those with lagophthalmos the cornea was exposed in 13 patients only and 8 of these had developed corneal opacity.

Out of 24 patients with corneal hypoaesthesia, 3 had developed corneal ulcers. Among 21 patients with corneal opacity, diminished corneal sensation could be detected in 16 patients.

Iris lesions, mostly atrophy, were confined to patients in the lepromatous spectrum of the disease. Iris pearls were seen in 2 patients out of 177 examined $(1.23 \%)$. Of the 7 cases with acute iritis, 5 were positive for lepra bacilli on routine skin smears from 4 sites. Among the 10 with chronic iridocyclitis, 5 had positive skin smears. Five patients with chronic iritis had a history of erythema nodosum leprosum reactions lasting for more than 6 months, and had been treated with both steroidal and non-steroidal anti-inflammatory drugs. The sequelae to iridocyclitis were occlusio pupillae, posterior synechiae and complicated cataract. 
Table 5 Eye lesions in relation to types of leprosy

\begin{tabular}{|c|c|c|c|c|c|c|}
\hline \multirow[b]{2}{*}{ Eye lesions } & \multicolumn{6}{|c|}{ Types of leprosy } \\
\hline & $\begin{array}{c}\text { All } \\
\text { types }\end{array}$ & LL & $\mathrm{BL}$ & BB & BT & $\mathrm{T} \& \mathrm{I}$ \\
\hline Madarosis & 135 & 87 & 38 & 1 & 9 & - \\
\hline Nasolacrimal duct blockage & 1 & - & - & - & 1 & - \\
\hline Lagophthalmos & 30 & 5 & 5 & 2 & 17 & $2 *$ \\
\hline Scleral and conjunctival lesions & 16 & 11 & 4 & - & 1 & - \\
\hline $\begin{array}{l}\text { Corneal lesions: } \\
\text { hypoaesthesia } \\
\text { opacities } \\
\text { ulcers }\end{array}$ & $\begin{array}{r}24 \\
21 \\
3\end{array}$ & $\begin{array}{r}10 \\
10 \\
2\end{array}$ & $\begin{array}{l}3 \\
5 \\
1\end{array}$ & $\frac{2}{-}$ & $\begin{array}{r}8 \\
6 \\
-\end{array}$ & $\frac{-}{-}$ \\
\hline $\begin{array}{l}\text { Iris lesions: } \\
\text { iritis - acute } \\
\text { chronic } \\
\text { iris atrophy } \\
\text { iris pearls }\end{array}$ & $\begin{array}{r}7 \\
10 \\
19 \\
2\end{array}$ & $\begin{array}{r}5 \\
9 \\
15 \\
2\end{array}$ & $\begin{array}{r}2 \\
1 \\
4 \\
-\end{array}$ & $\frac{-}{-}$ & $\begin{array}{l}- \\
- \\
-\end{array}$ & $\begin{array}{l}- \\
- \\
-\end{array}$ \\
\hline $\begin{array}{l}\text { Synechiae: } \\
\text { posterior } \\
\text { anterior }\end{array}$ & $\frac{10}{-}$ & $\begin{array}{l}7 \\
2\end{array}$ & 1 & - & - & - \\
\hline $\begin{array}{l}\text { Lens lesions complicated cataract } \\
\text { (secondary to iridocyclitis) }\end{array}$ & 2 & 2 & - & - & - & - \\
\hline
\end{tabular}

\footnotetext{
* There was 1 each in tuberculoid leprosy and indeterminate leprosy.
}

\section{Discussion}

To lose one's eyesight when the sense of touch is also gone is a real disaster. The purpose of the present study was to determine the magnitude of the eye problem in those who had visited the hospital for general leprosy care and not necessarily for the eye. It was noted that a vast majority of patients in the study group were ignorant of their eye problems even though a significant number among them required eye care.

Males seemed to be affected more than females, as observed by others. ${ }^{5,6}$ It is possible that more males seek medical attention or are more prone to injury by virtue of their outdoor work; however, the frequency is the same in each sex by type of leprosy, and the overall sex difference might therefore be due to the larger number of male patients seen with lepromatous leprosy.

Eye lesions were more common and severe in the lepromatous spectrum of the disease and with increased duration of the disease. There is thus a need for close monitoring of this group for early recognition of potentially sight threatening lesions.

To explain facial palsy in leprosy, one study ${ }^{7}$ postulated that leprous infections entered the malar skin through sensory fibres of the trigeminal nerve and ingressed into the cutaneous branches of the facial nerve with which they are in close proximity. In our series, among the 30 patients with lagophthalmos only 15 had corneal anaesthesia, indicating that facial nerve can be affected independent of trigeminal nerve involvement. Five patients with lagophthalmos but no corneal anaesthesia, had a history of reactions in the past which may account for the development of the facial palsy.

Corneal opacity was present with and without lagophthalmos. In the absence of lagophthalmos this could have developed as a sequelae to degenerative changes to which hypoaesthetic corneas are 
particularly prone. In the 5 patients who had corneal opacity without either lagophthalmos or demonstrable corneal hypoaesthesia it may have been due to healed corneal ulcers of unrecalled trauma.

Two out of 7 patients with acute iritis and 5 out of 10 patients with chronic iritis showed neither clinical nor bacteriological evidence of active disease. Reactions which frequently have acute iritis as one of their commonest features were also absent in these patients. It may be that the 2 patients with acute iritis were in a state of reaction, with iritis as the earliest single or more obvious feature. Such isolated tissue involvement in reaction is not uncommon as for instance in the case of neuritis. An alternative explanation is that the acute iritis represented an early reactivation of the disease which could not be detected at that time by routine skin smears f rom 4 sites. ${ }^{8}$ An iris which is derived of its nerve supply as a result of leprosy, tends to disintegrate. ffytche ${ }^{9}$ has suggested that such disintegrated muscle fibres can evoke inflammatory response leading to chronic iritis. This may explain the chronic iritis in 5 of the patients in our series in whom no active evidence of leprosy could be detected.

Glaucoma has been reported to be rare in leprosy because of atrophy and hyalinization of the ciliary body with diminished aqueous humour production. ${ }^{10,11}$ Also glaucoma was not detected in any of our patients. This however may not reflect the true incidence of glaucoma in leprosy, because our patients were screened on the basis of digital assessment of tension and tonometer assessment was made only where digital tension indicated increased pressure. Further, all patients were examined at a single point in time. With follow-up examination during episodes of iridocyclitis, perhaps more cases of glaucoma might have been picked up.

There is need for a practical scheme of classification and grading of eye lesions, for clear understanding and effective management. One study ${ }^{12}$ based their classification on pathogenesis, whereas WHO classification is on the basis of disability grading..$^{13} \mathrm{~A}$ simple but usef ul classification was suggested by Lamba ${ }^{14}$ wherein he divided the ocular lesions into 2 main categories: a, cosmetically disfiguring, e.g. madarosis; and b, potentially sight threatening. While Lamba's classification enables one to project the levels of ocular morbidity it does not adequately stress the importance of lesions like madarosis which can be significant from the patient's dehabilitation point of view. In our study 61 patients $(8 \cdot 22 \%)$ had potentially sight threatening lesions and 6 patients had become blind. The emphasis should be towards early detection and care for these.

While cross-sectional studies are useful to gauge the extent of eye morbidity, follow-up studies of those at high risk are necessary to determine incidence of this morbidity. Patients in the lepromatous spectrum of the disease, those with lagophthalmos and those with corneal lesions are particularly prone to silent but progressive eye lesions even after release from treatment. Follow-up studies will help in the further understanding of the pathogenesis and epidemiology of eye lesions due to leprosy.

\section{Acknowledgment}

I wish to record my indebtedness to Dr Rachel Mathai and Dr P S S Rao for the help in preparing this manuscript. I am grateful to the Director, Schieffelin Leprosy Research and Training Centre for permission to study their patients.

\section{References}

1 Reddy SC, Raja BD, Achary NRSB. Survey of eye complications in leprosy in Prakasam District (A.P). Lepr India, 1981; 53: 231-7.

2 Dutta LC, Das NC, Chatterjee BC, Bujarbarua D.N. Ocular lesions in leprosy. J Ind Med Assoc, 1973; 61: 385-7.

${ }^{3}$ ffytche TJ. A computer form to aid collection of data. Lepr Rev, 1983; 54: 271-81. 
4 Shields JA. George OW III, Luis GM. Ocular findings in leprosy. Am J Ophthalmol, 1974; 77: 880-90.

${ }^{5}$ Her Hsin Tsai, Suryawanshi N. Ocular complications in patients with leprosy in Karigiri, S. India. Lepr Rev, 1985; 56: 135-41.

${ }^{6}$ Mc Laren DS, Shaw MJ, Dalley KR: Eye diseases in leprosy patients - a study in central Tanganyika. Int J Lepr, 1961; 29: 20-8.

7 Dastur DK, Antia NH, Divakar SC. The Facial nerve in leprosy. Int J Lepr, 1966; 34: 117-38.

8 Suryawanshi N. Clinical manifestations of Iridocyclitis in leprosy. Ind J Lepr, 1985; 57: 549-55.

9 ffytche T J. Role of iris changes as a cause of blindness in Lepromatous leprosy. Br J Ophthalmol, 1981; 65: 231-9.

10 Pendergast JJ. Ocular leprosy in the U.S. Arch Ophthalmol, 1940; 23: 112-37.

11 Slem G. Clinical studies of ocular leprosy. Am J Ophthalmol, 1971; 71: 431-4.

12 Joffrion Von C, Brand M.E. Leprosy of the eye-A general outline. Lepr Rev, 1984; 55: 105-14.

13 WHO Report of the Consultation on disability prevention and rehabilitation in leprosy, Geneva, 9-11 March 1987. WHO/CDS/LEP/87-3.

${ }^{14}$ Lamba PA, Santhosh Kumar D, Arthanariswaran R. Ocular leprosy-A new perspective. Lepr India, 1983; 55: $490-4$. 